\title{
SCANNING ELECTRON MICROSCOPE EVALUATION OF THE MARGINAL GAP AND INTERNAL FIT OF ADDITIVE VERSUS SUBTRACTIVE FABRICATION TECHNIQUES FOR POSTERIOR LITHIUM DISILICATE CROWNS
}

\author{
Marwa Beleidy* and Ahmed Ziada**
}

\begin{abstract}
Statement of the problem: The wide use of digital dentistry in fixed prosthodontics using 3D printers and CAD/CAM in fabricating crowns and partial fixed dental prosthesis created a need for more information about their marginal gap and internal fit.

Purpose: This study aimed to evaluate the effect of fabrication technique using CAD/CAM manufactured and heat pressed lithium dislicate crowns made from milled wax and 3D printed resin patterns on their marginal gap and internal fit.
\end{abstract}

Material \& Methods: A total of 50 prepared mandibular first molar resin models were used and divided into two main groups according to their fabrication phase: Patterns group and fully fabricated crowns group. Patterns group was subdivided into milled wax patterns $(W)(n=10)$ and $3 \mathrm{D}$ printed resin patterns $(\mathrm{P})(\mathrm{n}=10)$. Fully fabricated crowns group was subdivided according to fabrication technique of lithium disilicate crowns into: Machinable ceramics (M), using IPS e-max CAD blocks $(n=10)$, Pressable ceramics (Pw), using IPS e-max press ingots following wax milling $(\mathrm{n}=10)$ and Pressable ceramics $(\mathrm{Pp})$, using IPS e-max press ingots following 3D resin printing $(n=10)$. All patterns and ceramic crowns were cemented with Rely-X self-adhesive resin cement. Marginal and internal adaptations were measured using SEM at $300 \times$ magnification. KruskalWallis and Wilcoxon signed-rank tests were applied to compare between the groups. Data were presented as median and range values. The significance level was set at $\mathrm{P} \leq 0.05$.

Results: P group showed a significant higher median total marginal gap of $111.4 \mu \mathrm{m}$ (80.8-139.7) than $\mathrm{W}$ group of $51.3 \mu \mathrm{m}$ (45.1-57.8) before heat pressing. While $\mathrm{M}$ group showed the significant highest median marginal gap of $138.4 \mu \mathrm{m}$ (83.4-191.8) and no significant difference between heat pressed groups ( $\mathrm{Pw}$ and $\mathrm{Pp})(\mathrm{P} \leq .05)$. Regarding changes after heat pressing, $\mathrm{Pw}$ group showed no significant decrease, while Pp group showed a significant decrease in median total marginal gap. For internal fit, there was no significant difference between the pattern groups

* Lecturer, Department of Fixed Prosthodontics, Faculty of Dentistry, October 6th University, Giza, Egypt.

** Lecturer, Department of Fixed Prosthodontics, Faculty of Dentistry, Benisuef University, Benisuef, Egypt. 
(W and $\mathrm{P}$ ) before heat pressing $(\mathrm{P} \leq .05)$. After heat pressing, Pp group showed the significantly highest median gap of $195 \mu \mathrm{m}$ (138.9-441.5) with no significant difference between $\mathrm{M}$ and $\mathrm{Pw}$ groups $(\mathrm{P} \leq .05)$. $\mathrm{Pw}$ group showed a significant decrease in median gap, and $\mathrm{Pp}$ group showed no significant decrease after pressing $(\mathrm{P} \leq .05)$.

Conclusions: Heat pressed lithium disilicate glass ceramic crowns produced from CAD/CAM waxing or resin 3D printing techniques resulted in better marginal and fit accuracy than CAD/CAM. 3D printed resin patterns yielded internal fit values higher than other groups, but with promising clinical acceptability.

Keywords: 3D printing, CAD/CAM, Heat pressed, Marginal gap and Internal fit.

Clinical implications: Both the additive and subtractive production for patterning phase before heat pressing allow clinical acceptability in terms of marginal and internal adaptation when a single unit posterior ceramic lithium disilicate crown is fabricated.

\section{INTRODUCTION}

With the new era of advanced digital dentistry, patterns fabrication based on high technology such as subtractive milling with Computer Aided Designing/Computer Aided Manufacturing (CAD/CAM) systems or additive manufacturing with 3D printing can be carried out. ${ }^{1}$ CAD/CAM systems main concept depends on computer aided designing and then computerized controlling of the milling machine to produce the final restoration. ${ }^{2}$ While Additive production based on dissembling the 3D CAD design into multi-slice images and make uninterrupted 5 to 20 layers for each millimeter of material, which are reunited to achieve the designed shape. ${ }^{3,4}$

Lithium disilicates gained its reputation because of their superior aesthetics, adhesive bonding ability, and their precise marginal fit. ${ }^{5,6}$ These restorations are typically fabricated from wax pattern by using CAD/CAM technology or heat pressing. But the question here what could direct a clinician to make CAD/CAM wax patterns to generate a heat pressed lithium disilicate crowns if they can directly manufacture milled crowns from lithium dislicate CAD blocks by the same CAD/CAM machine. Many reasons might arise answering such a question, but the clearest reasons are the higher cost of CAD/CAM fabricated crowns compared to the heat pressed crowns from a CAD/CAM wax patterns, also the researches that concluded pressed crowns had evidential better marginal adaptation than which made with $\mathrm{CAD} / \mathrm{CAM}$ method. ${ }^{7}$

Marginal accuracy is considered as one of the main requirements to assure a long term successful restorations. Leakage may cause biologic, mechanical or aesthetic hinderances. ${ }^{8,9}$ Most researchers utilized the standards initiated by McLean and Von Fraunhofer who stated that clinically accepted interface dimension is less than $120 \mu \mathrm{m} .{ }^{10}$ However, other researchers reported values in the literature from $50-200 \mu \mathrm{m} .^{9,11,12}$ There is no standardization due to many various methodologies used to assess the marginal accuracy. ${ }^{13}$ Measuring the marginal fit can be done directly or indirectly. ${ }^{14}$ One of the conservative techniques in addition to its superior magnification that gives adequate findings of the marginal and fit variance is the scanning electron microscope (SEM).

Consequently, in this study two types of lithium disilicate fabrication techniques (CAD/CAM technology and heat pressing) for the molar region were used. For heat pressing, two pattern fabrication techniques (milled waxing and 3D resin printing) were selected. This study was plotted to explore the vertical marginal gap of additive versus subtractive fabricated posterior lithium disilicate crowns and the internal fit parameters derived by SEM. The expected null hypothesis was that $3 \mathrm{D}$ printing could be statistically significant lower than subtractive 
fabrication techniques in the vertical marginal gap and internal fit.

\section{MATERIAL AND METHODS}

\section{Sample grouping}

Sample size was calculated based on large effect size ( $\mathrm{f}=0.838$ ), alpha error probability of $(\alpha=$ $0.05)$, power $(1-\beta$ err prob $=0.2)$ using the formula from the results taken from the previous studies. The $\mathrm{P}$ value set at 0.05 for the study. A total of 50 mandibular first molar tooth experimental models were used in this study and divided randomly according to tested groups (Table 1, 2). Sample size calculation was performed using a statistical power analyses software ( $\mathrm{G}$ *Power Version 3.1.9.2, Heinrich Heine University Düsseldorf, Germany).

\section{Abutment tooth preparation and experimental model fabrication}

To conduct this study, a lower master model (Model \#R861; Columbia Dentoform Corporation, Long Island City, NY, USA) of an ivorine lower first molar was created. Silicon indices were obtained from the unprepared tooth and used to check preparation depths. ${ }^{15}$ Tooth preparation was standardized to receive full coverage all ceramic crown with $12^{\circ}$ as a total convergence angle, a rounded shoulder margin of $1.0 \mathrm{~mm}$ thickness circumferentially, an anatomical occlusal reduction of $1.5 \mathrm{~mm}$ from pit and fissure, an axial reduction of $1.0-1.5 \mathrm{~mm}$ and a preparation height of $3.0 \mathrm{~mm}$. All sharp points and line angles were rounded off. ${ }^{16}$

Fifty half-arch impressions were made for the prepared tooth with a polyvinylsiloxane impression material (President Coltène, Coltène/ whaledent $\mathrm{GmbH}$, Germany) using one-step technique. The impression was inspected under fiber optic microscope $4 \mathrm{x}$ magnification for any tears or defects which if observed the impression was retaken again. Fifty epoxy resin models were fabricated accurately similar to the prepared abutment from the master model, on which the crowns were cemented using a dental epoxy resin material (Die Epoxy Type 8000 System, American Dental Supply, Inc,

TABLE (1) Patterns Grouping.

\begin{tabular}{cccc}
\hline \multirow{2}{*}{$\begin{array}{c}\text { Patterns } \\
\text { grouping }\end{array}$} & \multicolumn{1}{c}{ Groups } & Specimen No. & Manufactures \\
\cline { 2 - 4 } & Group 1(W) Milled wax & 10 & DMAX Co.,Ltd.,Korea. \\
\cline { 2 - 4 } & Group 2 (P) 3D printed resin & 10 & NextDent, NextDent B.V. \\
\hline
\end{tabular}

TABLE (2) Fully fabricated crowns grouping.

\begin{tabular}{cccc}
\hline & Groups & $\begin{array}{c}\text { Specimen } \\
\text { No. }\end{array}$ & Manufactures \\
\cline { 2 - 4 } $\begin{array}{c}\text { Fully } \\
\text { fabricated } \\
\text { crowns } \\
\text { grouping }\end{array}$ & Group 1 (M) CAD/CAM & 10 & $\begin{array}{c}\text { IPS e.max CAD, Ivoclar Vivadent, } \\
\text { Liechtenstein. }\end{array}$ \\
\cline { 2 - 4 } & $\begin{array}{c}\text { Group 2 }(\mathrm{Pw}) \text { Heat pressed milled } \\
\text { wax }\end{array}$ & 10 & $\begin{array}{c}\text { IPS e.max press, Ivoclar Vivadent, } \\
\text { Liechtenstein. }\end{array}$ \\
\cline { 2 - 4 } & $\begin{array}{c}\text { Group 3 (Pp) Heat pressed 3D } \\
\text { printed resin }\end{array}$ & 10 & $\begin{array}{c}\text { IPS e.max press, Ivoclar Vivadent, } \\
\text { Liechtenstein. }\end{array}$ \\
\hline
\end{tabular}


Allentown, PA, USA) that was blended following the manufacturer manual and was poured into fifty half arch impressions using one step technique. ${ }^{17}$

\section{Computer Aided Designing (CAD) of crowns and patterns}

The epoxy resin dies were scanned and digitized by using extra oral scanner (in Eos X5; Sirona Dental Systems GmbH, Bensheim, Germany). The e.max CAD crowns, wax, and resin crown patterns were designed according to the manufacturer specifications by using a software (Sirona inLab SW15 software; Sirona Dental Systems GmbH, Bensheim, Germany) (Fig. 1,2) The crowns and patterns were prepared with a cement space of $80 \mu \mathrm{m}$. After completion of the design, the standard tessellation language (STL) file was sent to the milling machine (Sirona MCX5, Sirona Dental Systems GmbH, Bensheim, Germany) to manufacture both the precrystalized e.max CAD crowns and wax patterns then it was sent to the $3 \mathrm{D}$ printer (Dent2 3D printer; Mogassam Co. LLC, Newark, DE, USA) to fabricate resin patterns.

\section{Subtractive fabrication}

After finishing the designing phase, lithium disilicate blocks (IPS e.max CAD, Ivoclar Vivadent, Liechtenstein), and wax blanks (DWAX - W14, DMAX Co.,Ltd.,Korea) were milled. Milled crowns (Fig. 3), and patterns were finished and checked for fitting on the corresponding epoxy resin dies. Finished e.max crowns were then crystallized and glazed following the manufacturer manual by using a specific furnace (Ivoclar Vivadent P3010 furnace, Ivoclar Vivadent, Liechtenstein).

\section{Additive fabrication}

The same design STL file was sent to a 3D printer to produce the resin patterns (NextDent Cast, NextDent B.V., Soesterberg, Netherlands) by using the Digital Light Processing (DLP). An acrylic esters-based monomer was poured in the

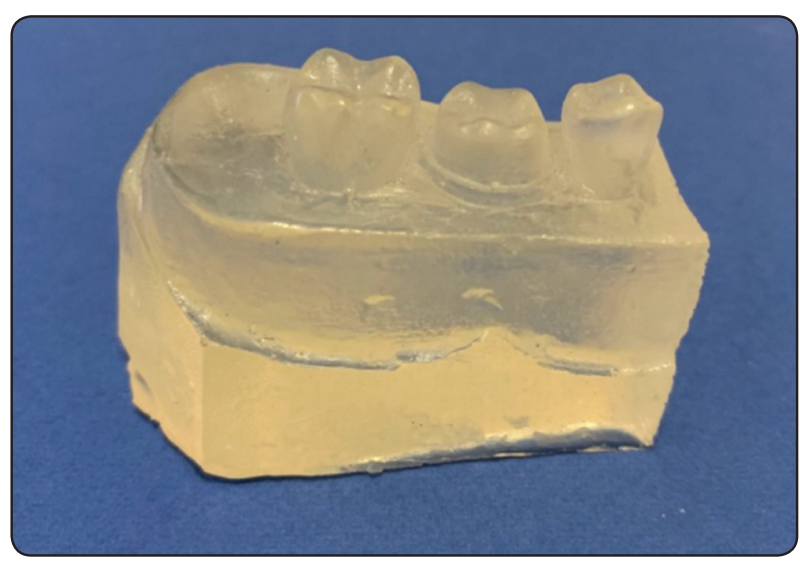

Fig. (1) Scanned epoxy resin die.

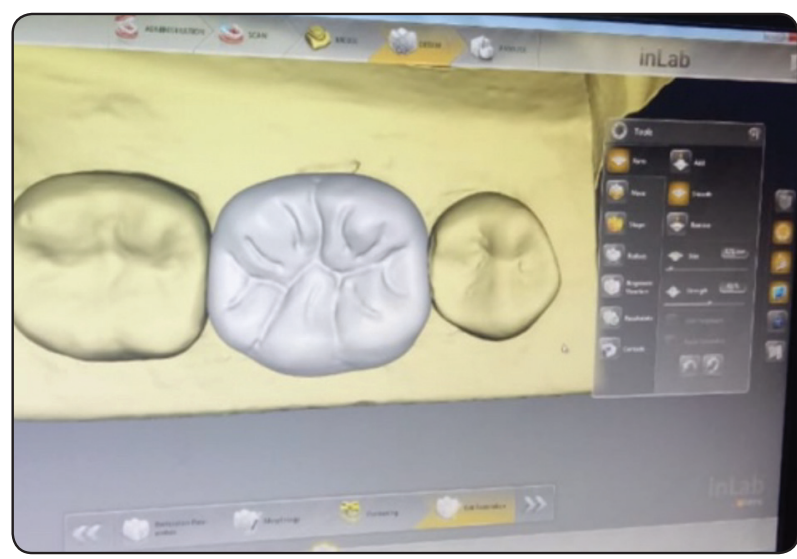

Fig. (2) Designing of e.max CAD crowns, wax, and resin crown patterns using Sirona in Lab SW15 software.

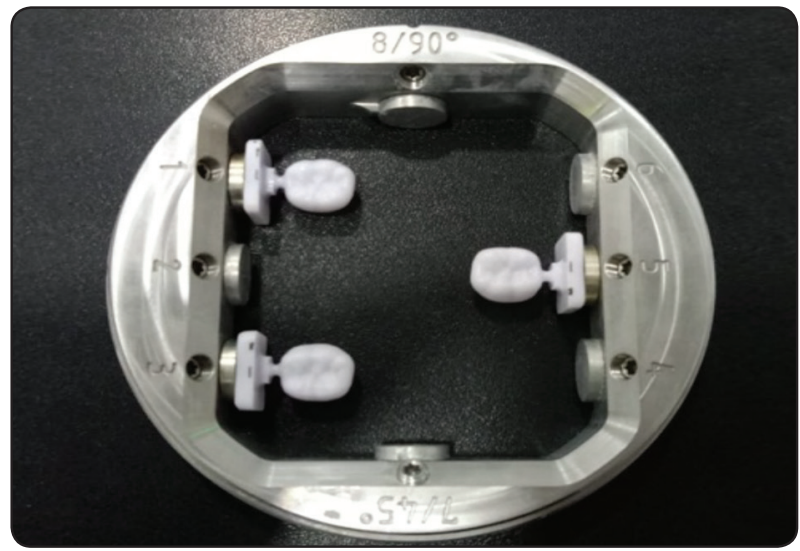

Fig. (3) Milled lithium disilicate crown samples. 
reservoir of the 3D printing machine. The machine was set up and printing was completed. Post curing with ultra violet (UV) light was done to ensure full polymer conversions following the manufacturer recommendation. Any support structures were removed and the printed crowns were finished (Fig. 4).

\section{Heat pressing}

After wax milling and resin patterns printing, the patterns were sprued, invested and heat pressed by the lost wax technique using lithium disilicate ingots (IPS e.max press, Ivoclar Vivadent, Liechtenstein), following the instructions recommended by the manufacture. After pressing, crowns were subjected to air abrasion with $100 \mu \mathrm{m}$ particles of aluminum oxides at $5 \mathrm{Mpa},{ }^{18}$ and the crowns were finished, glazed, and fitted to the corresponding epoxy resin dies (Fig. 5).

\section{Cementation of the crowns}

The epoxy resin dies were sandblasted with $50 \mu \mathrm{m}$ aluminum oxide particles (CEMAT NT4,Wassermann Dental Maschinen GmbH, Hamburg, Germany) at 2.8 bars for $13 \mathrm{sec}$ at a distance of $10 \mathrm{~mm}$, cleaned with water then dried with air. ${ }^{19}$ The resinous wax and resin crowns were

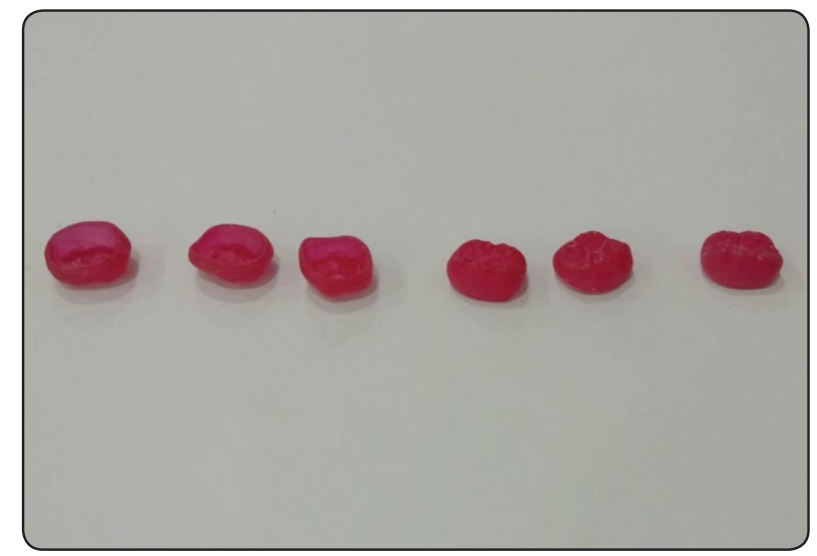

Fig. (4) Finished 3D printed resin crown samples. air-abraded with $50 \mu \mathrm{m}$ alumina powder for $10 \mathrm{~s}$ at a pressure of 2 bar and a distance of $10 \mathrm{~mm} .{ }^{20}$ All ceramic crowns were etched with $9 \%$ hydrofluoric acid gel (Pentron Clinical Technologies, LLC, Wallingford, CT, USA) for 60 seconds, flushed with water, and dried with air. Each crown then cemented to its corresponding epoxy master die with a selfadhesive resin cement (RelyX Unicem, 3M, ESPE, St. Paul MN) that was mixed according to the fabricator specifications and seated on the prepared dies with especially designed static loading device of $10 \mathrm{~kg}$ for 10 minutes to ensure an effective flow of the cement, maximum adaptation of the abutments (Fig. 6), ${ }^{21}$ surplus cement was cut off, and then the cement was light polymerized.

\section{Marginal gap and internal fit assessment}

Marginal gap was explored for both patterns and fully fabricated crowns on buccal and lingual surfaces by calibrating the vertical space between the restoration margin and the finishing line under SEM (Quanta 250 FEG Scanning Electron Microscope; FEI Company, Hillsboro, Oregon) with a magnification factor of $\times 300$ (Fig. 7-11). ${ }^{22}$ "As the optical axis of the microscope needs to be perpendicular to interface to guarantee a repeatable projection angle because of the shape of the crowns,

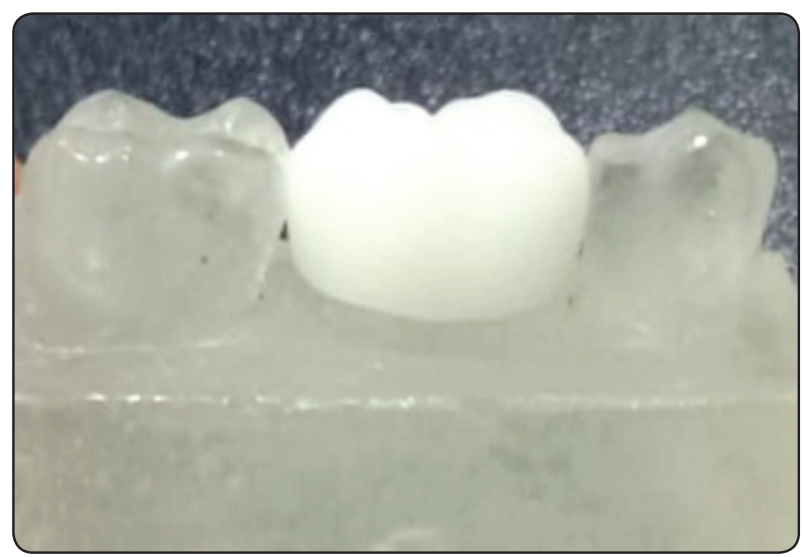

Fig. (5) Finished crown was fitted on its corresponding epoxy resin die. 
a specially designed metallic holder angled with 25 degrees was used then data were collected by digitizing the captured images by using a software (INCA suite 4.04 software; Oxford Instruments Analytical, Oxford, UK). ${ }^{23,24}$ To have more recorded calibrations for each specimen, lines were drawn parallel to the aboriginal line, up till 29 lines on each SEM image using design software (Adobe Photoshop CS6, Adobe Systems, San Jose, CA). ${ }^{13,23-}$ ${ }^{26}$ Sixty readings were recorded for each crown (30 per surface). The specimens were then deeply seated in a thermally polymerized resin (Die Epoxy Type 8000 System, American Dental Supply, Inc, Allentown, PA, USA) after the marginal fit evaluation and cut into longitudinal sections buccolingually to evaluate the internal fit by using micro saw (isoMet 4000; BUEHLER, Lake Bluff, IL, USA) with cooling system according to the isoMet manual instructions. Then samples were polished in a grinding machine (PT 251, Metasinex, Nordrhein-Westfalen, Germany) and the cement thickness representing the focal length between the fitting surface of the crown and the prepared tooth surface of the sectioned samples was used to clarify the internal fit and was measured similarly to the marginal gap using SEM (Fig.12 -16).

\section{Statistical Analysis}

Numerical data were investigated for normality utilizing Kolmogorov-Smirnov and ShapiroWilk tests. All data exhibited non-normal (nonparametric) distribution, they were showed as median and range values. Kruskal-Wallis test was applied to compare between the groups. Dunn's test was implemented for pair-wise comparisons. Wilcoxon signed-rank test was utilized to compare between gap values before and after heat pressing. The significance level was set at $\mathrm{P} \leq 0.05$. Statistical analysis was done using IBM (IBM Corporation, NY, USA) SPSS (SPSS, Inc., IBM, Armonk, NY, USA) Statistics Version 20 for Windows.

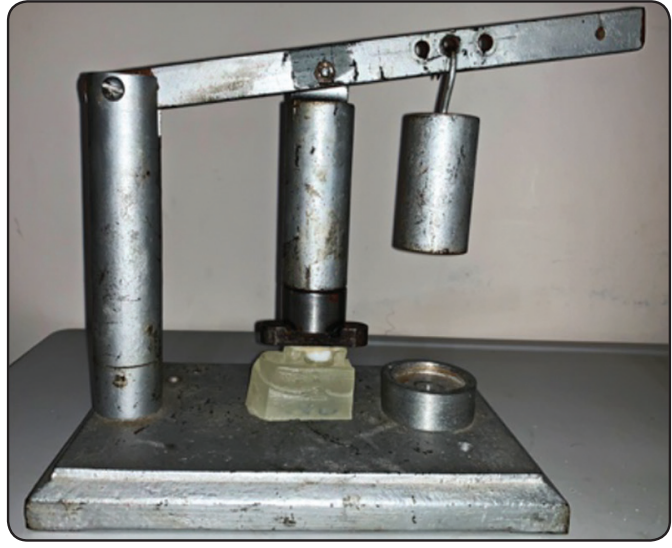

Fig. (6) An especially designed static loading device to ensure an effective flow of the cement and maximum adaptation during cementation.

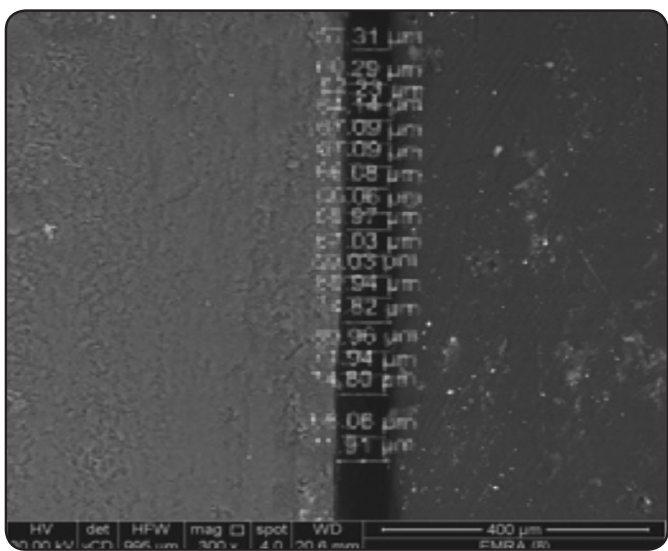

Fig. (7) Representative SEM image (magnification $\times 300$ ), showing the marginal gap of milled wax pattern before heat pressing (left: pattern, right: epoxy resin abutment).

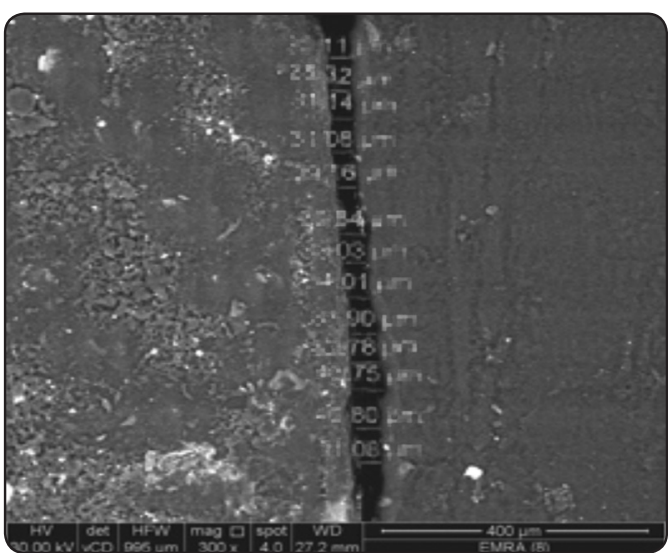

Fig. (8) Representative SEM image (magnification $\times 300$ ), showing the marginal gap of $3 \mathrm{D}$ printed resin pattern before heat pressing (left: epoxy resin abutment, right: pattern). 


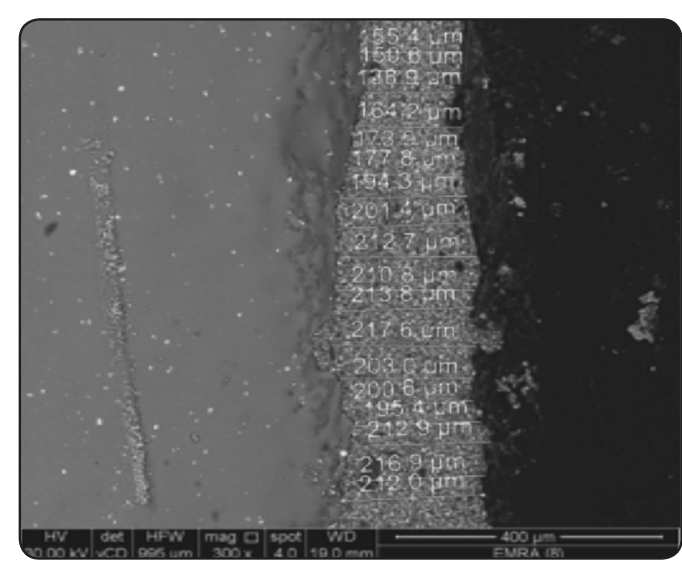

Fig. (9) Representative SEM image (magnification $\times 300$ ), showing the marginal gap of e.max CAD crown (left: ceramic, right: epoxy resin abutment)

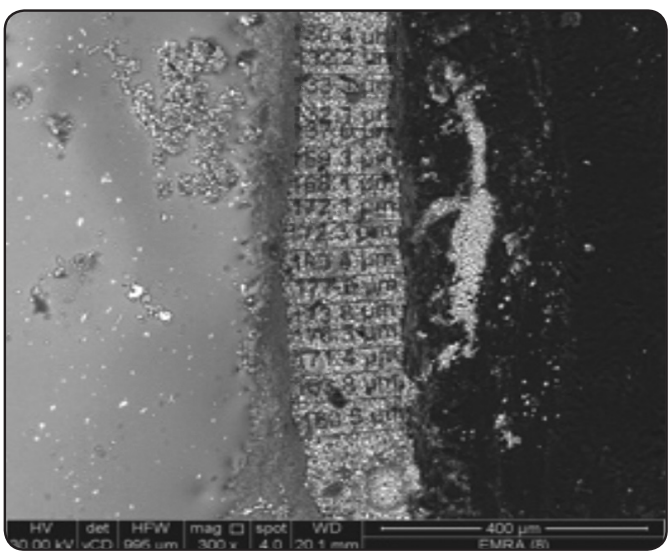

Fig. (11) Representative SEM image (magnification $\times 300$ ), showing the marginal gap of e.max press crown from 3D printed resin pattern (left: ceramic, right: epoxy resin abutment).

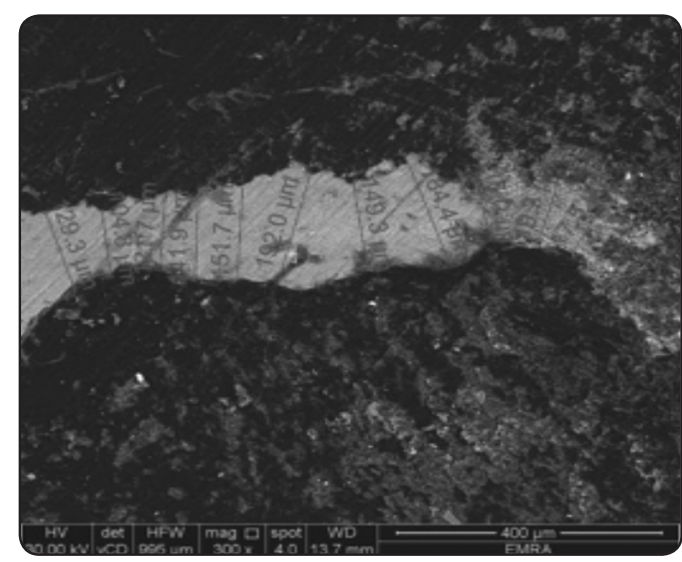

Fig. (13) Representative SEM image (magnification $\times 300$ ), showing the internal gap of $3 \mathrm{D}$ printed resin pattern before heat pressing (up: pattern, down: epoxy resin abutment).

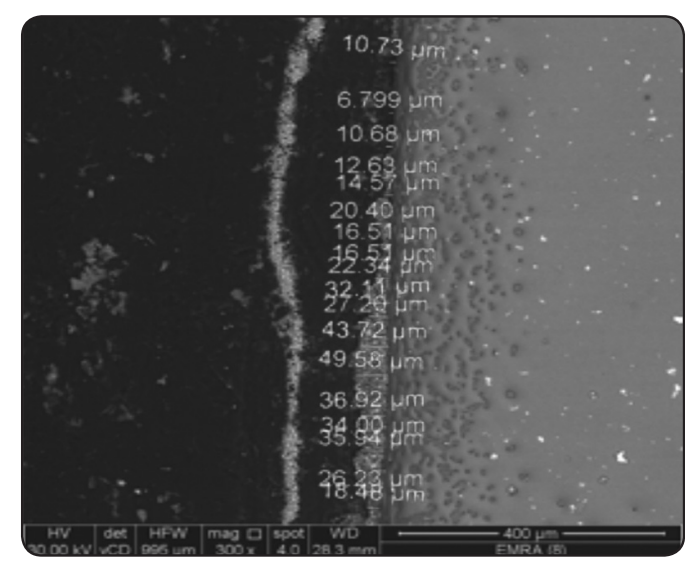

Fig. (10) Representative SEM image (magnification $\times 300$ ), showing the marginal gap of e.max press crown from milled wax pattern (left: epoxy resin abutment, right: ceramic).

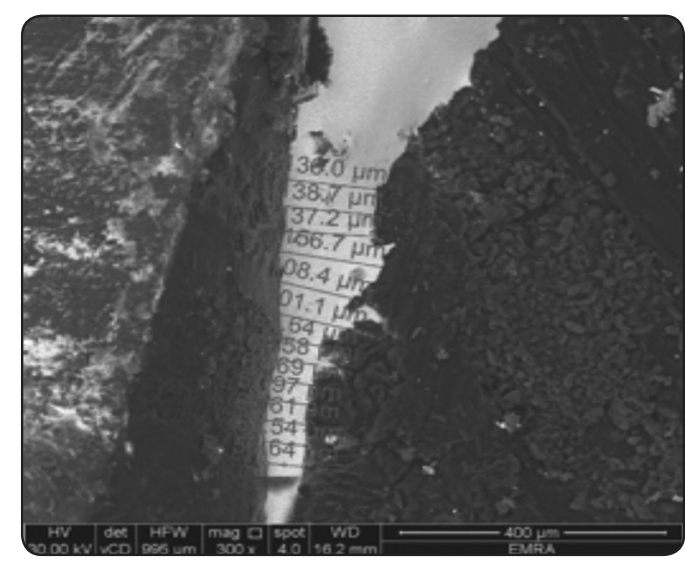

Fig. (12) Representative SEM image (magnification $\times 300$ ), showing the internal gap of milled wax pattern before heat pressing (left: pattern, right: epoxy resin abutment).

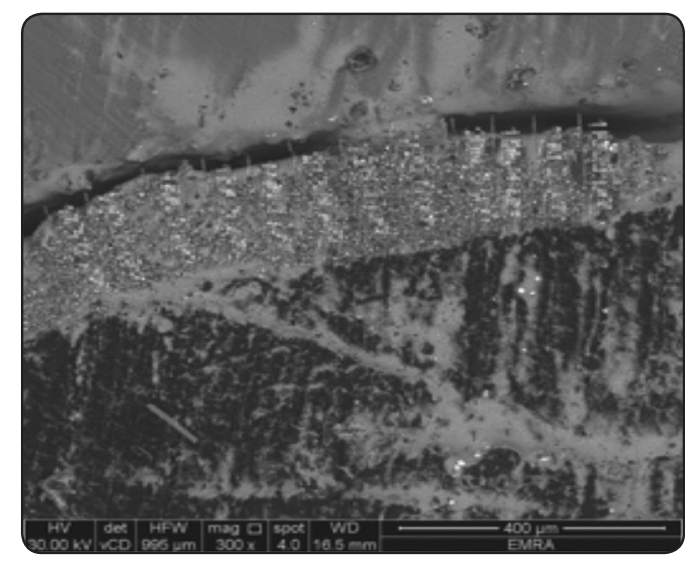

Fig. (14) Representative SEM image (magnification ×300), showing the internal gap of e.max CAD crown (up: ceramic, down: epoxy resin abutment). 


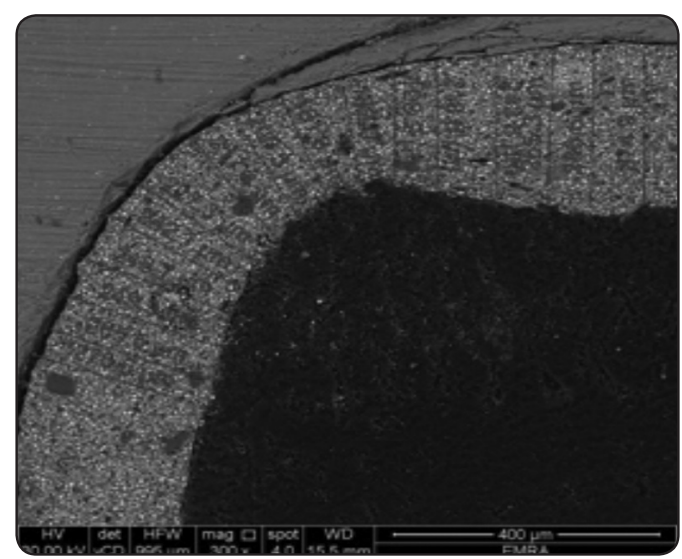

Fig. (15) Representative SEM image (magnification $\times 300$ ), showing the internal gap of e.max press crown from milled wax pattern (up: ceramic, down: epoxy resin abutment).

\section{RESULTS}

Statistical results for marginal gap were summarized (Table 3, 4). Before heat pressing, at the buccal and lingual surfaces, there was no statistically evidential divergence between marginal gap for pattern groups ( $\mathrm{W}$ and $\mathrm{P})(\mathrm{P} \leq .05)$. However, regarding the total gap, there was a statistically fundamental change between the two groups where P group showed higher median value of $111.4 \mu \mathrm{m}$ (80.8-139.7) ( $\mathrm{P} \leq .05)$. After heat pressing, at the buccal and lingual surface as well as total gap, there was a statistically evidential variance between the fully fabricated crown groups $(\mathrm{P} \leq .05)$. $\mathrm{M}$ group showed the statistically significant highest median gap of $138.4 \mu \mathrm{m}$ (83.4-191.8) and there was no statistically fundamental change between $\mathrm{Pw}$ and Pp groups; both showed statistically significantly lower median value $(\mathrm{P} \leq .05)$. Regarding the changes after heat pressing in $\mathrm{Pw}$ group, there was no statistically decreasing significance in median marginal gap at the buccal and lingual surfaces as

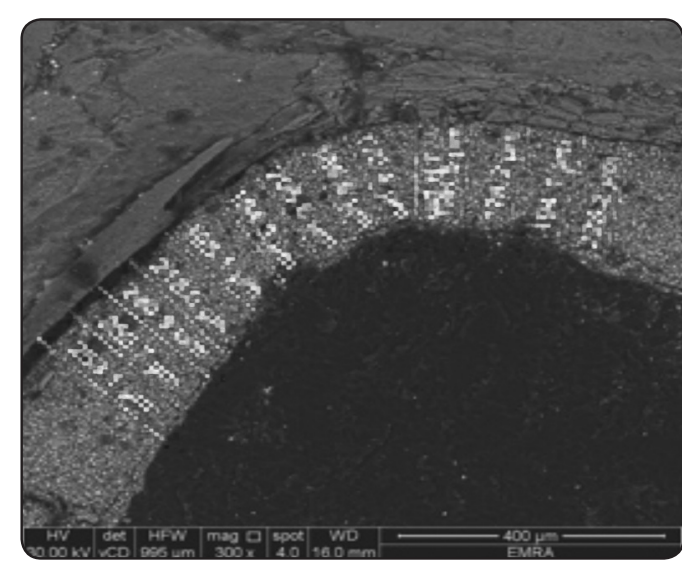

Fig. (16) Representative SEM image (magnification $\times 300$ ), showing the internal gap of e.max press crown from $3 \mathrm{D}$ printed resin pattern (up: ceramic, down: epoxy resin abutment).

well as for the total gap. While for the changes after heat pressing in Pp group, there was a statistically significant decrease in median marginal gap at the buccal and lingual surfaces as well as for the total gap $(\mathrm{P} \leq 0.05)$

Statistical results for internal fit were summarized (Table 5,6). Before heat pressing, there was no statistically fundamental variance between the pattern groups (W and $\mathrm{P})(\mathrm{P} \leq 0.05)$. After heat pressing, a statistically evidential change in fully fabricated crown groups was found. Pp group demonstrated the statistically evidentially highest median gap of $195 \mu \mathrm{m}$ (138.9-441.5). No statistically fundamental change between $\mathrm{M}$ and $\mathrm{Pw}$ groups was found, both demonstrated the statistically evidential lowest median gap values $(\mathrm{P} \leq 0.05)$. While for the changes after heat pressing in $\mathrm{Pw}$ group, there was a statistically decreasing significance in median gap. Considering the changes after heat pressing in $\mathrm{Pp}$ group, no statistically decreasing significance in median gap was exhibited $(\mathrm{P} \leq 0.05)$. 
TABLE (3) Descriptive statistics and results of Wilcoxon signed-rank test for comparison between marginal gap $(\mu \mathrm{m})$ of milled wax and 3D printed resin groups before and after heat pressing.

\begin{tabular}{ccccccc}
\hline \multirow{2}{*}{ Group } & Surface & $\begin{array}{c}\text { Before heat pressing } \\
\text { Median (Range) }\end{array}$ & $\begin{array}{c}\text { After heat pressing } \\
\text { Median (Range) }\end{array}$ & P-value & Effect size (r) \\
\hline \multirow{2}{*}{ Milled wax } & Buccal & $83.1(67.5-91.5)$ & $69.2(62.4-73.1)$ & .068 & 0.618 \\
\cline { 2 - 6 } & Lingual & $23.8(7.2-31.3)$ & $13.3(10.9-14.2)$ & .144 & 0.731 \\
\cline { 2 - 6 } & Total & $51.3(45.1-57.8)$ & $40.5(38.2-43.6)$ & .068 & 0.618 \\
\hline \multirow{2}{*}{ 3D printed resin } & Buccal & $158.6(51-202.3)$ & $35(26-102.8)$ & $.048^{*}$ & 0.715 \\
\cline { 2 - 6 } & Lingual & $77.2(51.4-110.5)$ & $25.1(15-44.7)$ & $.018^{*}$ & 0.894 \\
\cline { 2 - 6 } & Total & $111.4(80.8-139.7)$ & $27.1(26.3-73.8)$ & $.018^{*}$ & 0.894 \\
\hline
\end{tabular}

*: Significant at $P \leq .05$, Different superscripts in the same row are statistically significantly different.

TABLE (4) Descriptive statistics and results of Kruskal-Wallis test for comparison between marginal gap $(\mu \mathrm{m})$ of the fully fabricated crowns groups.

\begin{tabular}{cccccc}
\hline $\begin{array}{c}\text { Surface marginal gap } \\
\text { Median (Range) }\end{array}$ & $\begin{array}{c}\text { CAD/CAM } \\
(\mathrm{M})\end{array}$ & $\begin{array}{c}\text { Heat pressed milled } \\
\text { wax (Pw) }\end{array}$ & $\begin{array}{c}\text { Heat pressed 3D } \\
\text { printed resin (Pp) }\end{array}$ & $\begin{array}{c}\text { P-value } \\
\text { Effect size (Eta } \\
\text { Squared) }\end{array}$ \\
\hline Buccal & $140.9(77.8-191.8)^{\mathrm{A}}$ & $69.2(62.4-73.1)^{\mathrm{B}}$ & $35(26-102.8)^{\mathrm{B}}$ & $.014^{*}$ & 0.596 \\
\hline Lingual & $122.1(69.4-279.5)^{\mathrm{A}}$ & $13.3(10.9-14.2)^{\mathrm{B}}$ & $25.1(15-44.7)^{\mathrm{B}}$ & $.008^{*}$ & 0.625 \\
\hline Total & $138.4(83.4-191.8)^{\mathrm{A}}$ & $40.5(38.2-43.6)^{\mathrm{B}}$ & $27.1(26.3-73.8)^{\mathrm{B}}$ & $.049^{*}$ & 0.313 \\
\hline
\end{tabular}

*: Significant at $P \leq .05$, Different superscripts in the same row are statistically significantly different.

TABLE (5) Descriptive statistics and results of Wilcoxon signed-rank test for comparison between internal fit $(\mu \mathrm{m})$ before and after heat pressing in milled wax and 3D printed resin groups.

\begin{tabular}{ccccc}
\hline Group & $\begin{array}{c}\text { Before heat pressing Median } \\
\text { (Range) }\end{array}$ & $\begin{array}{c}\text { After heat pressing Median } \\
\text { (Range) }\end{array}$ & P-value & Effect size (r) \\
\hline Milled wax & (W) $272(174.5-375)$ & $(\mathrm{Pw}) 113.1(71.8-275.7)$ & $.028 *$ & 0.899 \\
\hline 3D printed resin & (P) $233.7(126.4-364.1)$ & $(\mathrm{Pp}) 195(138.9-441.5)$ & .401 & 0.297 \\
\hline
\end{tabular}

*: Significant at $P \leq .05$.

TABLE (6) Descriptive statistics and results of Kruskal-Wallis test for comparison between internal fit $(\mu \mathrm{m})$ of the fully fabricated crowns groups.

\begin{tabular}{cccccc}
\hline & $\begin{array}{c}\text { CAD/CAM } \\
(\mathrm{M})\end{array}$ & $\begin{array}{c}\text { Heat pressed milled } \\
\text { wax (Pw) }\end{array}$ & $\begin{array}{c}\text { Heat pressed 3D } \\
\text { printed resin (Pp) }\end{array}$ & $\begin{array}{c}\text { P-value } \\
\text { Effect size } \\
\text { (Eta Squared) }\end{array}$ \\
\hline $\begin{array}{c}\text { Internal fit Median } \\
(\text { Range })\end{array}$ & 87.5 & 113.1 & 195 & $.035^{*}$ & 0.200 \\
\hline
\end{tabular}

*: Significant at $P \leq .05$, Different superscripts in the same row are statistically significantly different. 


\section{DISCUSSION}

Since fit precision and internal adaptation are main factors affecting the restorations success, ${ }^{15}$ this study was aimed to assess marginal gap and internal fit of additive versus subtractive fabrication techniques for posterior lithium disilicate crowns.

In order to standardize the specimen preparation, the preparation was designed and replicated on epoxy resin dies according to preparation guidelines for all ceramic crowns mentioned in the literature. ${ }^{16,17}$ Also manufacturing conditions were standardized by scanning of the epoxy resin dies with the same extra oral scanner and the milling was done with the same milling machine by using a new set of diamond burs. Furthermore, the same operator fabricated all restorations as the dental technician factor could affect the results. ${ }^{10,13}$

In the current study, the crowns were luted to emulate clinical situations as investigation without cement does not match the real clinical condition..$^{10,27}$ However, studies analyzing marginal gap before and after cementation had determined that cement had a negative consequence on the marginal gap that was exaggerated after cementation..$^{27-29}$

The crown fit was evaluated on basis of that the vertical gap assessment is the most critical factor of marginal gap with least liability to post fabrication manipulation, as informed by Holmes et al. in $1989 .{ }^{22}$

Various measurements have been derived in many studies analyzing the marginal gap of ceramic crowns. The starring disadvantage of contrasting the different studies results arises from the lack of methodology standardization. ${ }^{10,15,30}$ In the current study, marginal gap and internal fit were investigated by direct screening on a SEM. This methodology has the vantages of placing samples in a base for standard calibrations and analyzing them under superior magnifying power, a parameter essential for this technique precision. ${ }^{15}$ In addition, this methodology minimizes the error chances replica production. ${ }^{31}$ To overcome the difficulties of repeating records from an identical angle, ${ }^{32}$ in this study experimental restorations were used and positioned on a base to ensure a repeatable measurements from the same point..$^{10,13,15,23,25}$

The measurements number per sample is a variable parameter that differs between studies. It falls between four and more than 100 sites per sample..$^{25,32}$ Nearly 50 sites of measurement per specimen would give an accordant evaluation of the misfit. ${ }^{25}$ No criterion for marginal gap measurements needed for in vitro evaluation has been set up, 60 measurements per specimen were obtained in this study to increase number of measurement points and obtain more reliable results.

In terms of margin discrepancy, before heat pressing in comparison to milled wax, 3D printing (P group) gave poorer results of $111.4 \mu \mathrm{m}$ (80.8139.7). Our null hypothesis expected that printing technology might be superior to wax milling for the crowns fabrication. However, this study results did not promote this, they reported that additive fabrication technique used in this study showed a lower margin discrepancy than milled wax patterns. This can be explained by limitations related to resin material used in 3D printing which is susceptible to polymerization shrinkage.

The optimum value for the marginal gap and internal fit are still a controversial point, however, they are considered as rudimentary parameters in the clinical long term partial fixed dental prosthesis success. ${ }^{33,35}$ In our study, the crowns obtained by milled e-max blocks showed a marginal gap of 138.4 $\mu \mathrm{m}$ (83.4-191.8) that was within reported marginal gap values ranging from 100-200 $\mu \mathrm{m}$ in other researches ${ }^{35-37}$ and in controversy to McLean and Von Fraunhofer's finding where marginal gap value less than $120 \mu \mathrm{m}$ is accepted clinically. ${ }^{11}$ While both heat pressed crowns from milled wax (40.5 $\mu \mathrm{m}$ [38.2-43.6]) and additive resin 
(27.1 $\mu \mathrm{m}$ [26.3-73.8]) followed their acceptable marginal gap values.

The results of our study illustrated statistically fundamental variance between the marginal fit of $\mathrm{CAD} / \mathrm{CAM}$ and heat pressed lithium disilicate crowns. The median marginal gap values in the heat pressed groups that were $40.5 \mu \mathrm{m}$ (38.2-43.6) for $\mathrm{Pw}$ group and 27.1 $\mu \mathrm{m}$ (26.3-73.8) for Pp group, were lower than the CAD/CAM group value which was 138.4 $\mu \mathrm{m}$ (83.4-191.8). This research results agreed with other studies that claimed lesser marginal gap for the restorations made of heat pressed technique compared to those made of CAD/CAM lithium disilicate ones. ${ }^{38-40}$ However, Guess et al detected no evidential change between the gap of CAD/CAM lithium disilicate (CEREC 3D InLab) and heat pressed onlays. ${ }^{40}$ Moreover, $\mathrm{Ng}$ et al disclosed lesser gap in CAD/CAM lithium disilicate (LAVA C.O.S. scanning unit) than heat pressed crowns. ${ }^{41}$ These conflicts might be explained by the difference in $\mathrm{CAD} / \mathrm{CAM}$ units, microscopes, and magnifications utilized in their studies and our current study. While Neves et al recorded no fundamental variance in marginal gap between IPS e.max press crowns and IPS e.max CAD crowns fabricated by the CEREC inLab MC XL. ${ }^{38}$

For CAD/CAM manufactured restorations, past studies concentrated on internal and marginal fit of lithium disilicate crowns, and both materials gave internal and marginal crown adaptation results within clinically accepted range., ${ }^{6,37,41,42-48}$ In this study, the marginal gap and internal fit values of lithium disilicate crowns gave higher recorded values than those of preceding studies. This may be explained by setting of the spacer thickness at $80 \mu \mathrm{m}$ used in this study as it is included in the CAD/CAM settings. It has been documented that various settings have an impact on the marginal and internal fit. ${ }^{49-51}$ Mously et al examined the impact of die spacer thickness on restorations fit produced with E4D CAD/ CAM system, and they suggested a spacer thickness of 30 or $60 \mu \mathrm{m} \cdot{ }^{37}$ Hence there is no enough data for the impact of optimum spacer thickness on CEREC crowns fit, further studies should be done to investigate the adequate spacer thicknesses for CEREC crowns fabricated from various materials.

In this study, $\mathrm{Pw}$ group (40.5 $\mu \mathrm{m}$ [38.2-43.6]) and Pp group (27.1 $\mu \mathrm{m}$ [26.3-73.8]) showed significantly the lower value and both were better than CAD/CAM (138.4 $\mu \mathrm{m}$ [83.4-191.8]) and this might be explained by the difference of material behaviors in heat pressing technique.

In the additive processing, marginal gap showed significantly the lowest value (27.1 $\mu \mathrm{m}$ [26.3-73.8]). The factors that might have the major influence on the results are the build direction axes. The stairstepping may have impacted on the dimensional accuracy of the pattern parts. This study showed a variance between titular values and internal fit results. This could be due to distortion of pattern parts during the polymerizing process as it is combined with a lot of heat influencing the interlayer binding which could be dominated by the photoinitiator incorporated in the polymer and by the irradiant exposure situations (power, wavelength, and exposure time/velocity). ${ }^{52-55}$ This in accordance with the results of the margins, as it is the last layer formed and it will be less involved by these factors. In additive fabrication, errors assembled at high curvature areas. ${ }^{56}$ This conclusion clarifies the variance between titular values and internal fit results. Moreover, putting into consideration that such group had the heat pressing technique advantages and was avoided the drawbacks of milling phase.

A statistically decreasing significance in median gap was detected in $\mathrm{Pw}$ group that was $40.5 \mu \mathrm{m}$ (38.2-43.6) after heat pressing. While the wax utilized for CAD/CAM is a solid manufactured wax composed by polymerization and is less sensitive to temperature changes ${ }^{57}$ and this was not supported by our study that needs to clarify. 
Internal gaps values recorded in the current study were $87.5 \mu \mathrm{m}$ (42.7-269.1), $113.1 \mu \mathrm{m}$ (71.8-275.7) and $195 \mu \mathrm{m}$ (138.9-441.5) for M, Pp and Pw groups respectively and all were within the range (200-300 $\mu \mathrm{m})$ of clinically accepted internal gap for luted restorations.$^{58}$ The e.max press crowns generated from additive technique $(\mathrm{Pp})$ showed the statistically significant highest internal misfit. These results were disagreed with those of Fathi et al who found that 3D printed wax crowns showed better accuracy than milled ones with the similar design..$^{59}$ Other study reporting that e.max press crowns fabricated from milled wax blocks or additive wax were not evidentially variant. ${ }^{60}$ These controversies could be due to the 3D printers nonstandard accuracy, different materials, and techniques used to assess fit accuracy, ${ }^{3}$ in addition to the geometrically complex areas of the preparations with curvatures and angels which may be accompanied with low scanning accuracy ${ }^{61,62}$ Also putting into considerations that the corrugated or sloping surfaces had an adverse effect on the 3D printed patterns accuracy causing higher values of internal discrepancies. ${ }^{63}$

While for the changes after pressing in $\mathrm{Pw}$ group, there was a statistically decreasing significance in median gap from $272 \mu \mathrm{m}$ (174.5-375) to $113.1 \mu \mathrm{m}$ (71.8-275.7). This may be due to material behavior during heat pressing that needs further investigation to be explained.

As a limitation of this study, it was contributed only to lithium disilicate material. So, the results can't be shared with other restoration types or restorative materials. The current study contrasted the heat pressing approach to a specific CAD/CAM system, which makes the results irrelevant to other CAD/CAM systems. A standardized fabrication was used to produce the crowns which may not mimic the clinical work where the restoration adaptation could be affected by abutment preparation, impression technique, and cementation. Even though the deficiencies, this study has some optimistic features giving significant information to the field. The marginal gap was recorded at 60 points of each specimen, decreasing calibration errors and allowing the circumferential margin of the restoration to be evaluated with the superior accuracy.

Despite this limitation, the reported data provides researchers with a significant start to direct future clinical research hypotheses. In addition, more studies are needed in three distinct areas: to investigate the ability of achieving these marginal gaps clinically, the impacts of them on the restorations durability and to study marginal accuracy across different restorative materials, finish line designs, and impression techniques.

\section{CONCLUSIONS}

The heat pressing fabrication technique after wax pattern milling and 3D resin pattern printing showed the best marginal fit $(40.5 \mu \mathrm{m}$ and 27.1 $\mu \mathrm{m})$. The heat pressed lithium disilicate crowns obtained by $3 \mathrm{D}$ printed patterns was within reported clinically accepted marginal adaptation values. In spite of the highest CAD/CAM fabricated lithium disilicate crowns marginal gap $(138.4 \mu \mathrm{m})$, they are considered within the reported clinically accepted marginal adaptation values.

\section{REFERENCES}

1. Zarone F, Ferrari M, Mangano FG, Leone R, Sorrentino R. "Digitally oriented materials": focus on lithium disilicate ceramics. International journal of dentistry. 2016;2016.

2. Alghazzawi TF. Advancements in CAD/CAM technology: Options for practical implementation. Journal of prosthodontic research. 2016 Apr 1;60:72-84.

3. Abduo J, Lyons K, Bennamoun M. Trends in computeraided manufacturing in prosthodontics: a review of the available streams. International journal of dentistry. 2014;2014

4. Keating AP, Knox J, Bibb R, Zhurov AI. A comparison of plaster, digital and reconstructed study model accuracy. Journal of orthodontics. 2008 Sep 1;35:191-201. 
5. Ritter RG. Multifunctional Uses of a Novel CeramicLithium Disilicate. Journal of Esthetic and Restorative Dentistry. 2010 Oct;22:332-41.

6. Baig MR, Tan KB, Nicholls JI. Evaluation of the marginal fit of a zirconia ceramic computer-aided machined (CAM) crown system. The Journal of prosthetic dentistry. 2010 Oct 1;104:216-27.

7. Mounajjed R, Layton DM, Azar B. The marginal fit of E. max Press and E. max CAD lithium disilicate restorations: A critical review. Dental materials journal. 2016 Nov 28;35:835-44.

8. Knoernschild KL, Campbell SD. Periodontal tissue responses after insertion of artificial crowns and fixed partial dentures. The Journal of prosthetic dentistry. 2000 Nov 1;84:492-8

9. Martínez-Rus F, Suárez MJ, Rivera B, Pradíes G. Evaluation of the absolute marginal discrepancy of zirconia-based ceramic copings. The Journal of prosthetic dentistry. 2011 Feb 1;105:108-14.

10. McLean JW. The estimation of cement film thickness by an in vivo technique. Br dent j. 1971;131:107-11.

11. Gonzalo E, Suárez MJ, Serrano B, Lozano JF. Marginal fit of Zirconia posterior fixed partial dentures. International Journal of Prosthodontics. 2008 Sep 1;21

12. Gonzalo E, Suárez MJ, Serrano B, Lozano JF. A comparison of the marginal vertical discrepancies of zirconium and metal ceramic posterior fixed dental prostheses before and after cementation. The Journal of prosthetic dentistry. 2009 Dec 1;102:378-84.

13. Mitchell CA, Pintado MR, Douglas WH. Nondestructive, in vitro quantification of crown margins. The Journal of prosthetic dentistry. 2001 Jun 1;85:575-84.

14. Gonzalo E, Suarez MJ, Serrano B, Lozano JF. Comparative analysis of two measurement methods for marginal fit in metal-ceramic and zirconia posterior FPDs. International Journal of Prosthodontics. 2009 Jul 1;22.

15. Ram HK, Shah RJ, Agrawal HS. Evaluation of three different tooth preparation techniques for metal ceramic crowns by comparing preparation depths: An in vitro study. The Journal of the Indian Prosthodontic Society. 2015 Apr;15(2):162.

16. Goodacre CJ, Campagni WV, Aquilino SA. Tooth preparations for complete crowns: an art form based on scientific principles. The Journal of prosthetic dentistry. 2001 Apr 1;85:363-76.
17. Aiach D, Malone WF, Sandrik J. Dimensional accuracy of epoxy resins and their compatibility with impression materials. Journal of Prosthetic Dentistry. 1984 Oct $1 ; 52: 500-4$.

18. Schaefer O, Watts DC, Sigusch BW, Kuepper H, Guentsch A. Marginal and internal fit of pressed lithium disilicate partial crowns in vitro: a three-dimensional analysis of accuracy and reproducibility. Dental Materials. 2012 Mar $1 ; 28: 320-6$.

19. Yucel MT, Yondem I, Aykent F, Eraslan O. Influence of the supporting die structures on the fracture strength of allceramic materials. Clinical oral investigations. 2012 Aug 1;16:1105-10.

20. Stawarczyk B, Bauer F, Ender A, Roos M, Dalhoff D, Swimmer T. Influence of cementation and cement type on the fracture load testing methodology of anterior crowns made of different materials. Dental materials journal. 2013 Nov 28;32(6):888-95.

21. Proussaefs P. Crowns cemented on crown preparations lacking geometric resistance form. Part II: effect of cement. Journal of Prosthodontics: Implant, Esthetic and Reconstructive Dentistry. 2004 Mar;13(1):36-41.

22. Holmes JR, Bayne SC, Holland GA, Sulik WD. Considerations in measurement of marginal fit. The Journal of prosthetic dentistry. 1989 Oct 1;62:405-8.

23. Oyagüe RC, Sánchez-Turrión A, López-Lozano JF, Suárez-García MJ. Vertical discrepancy and microleakage of laser-sintered and vacuum-cast implant-supported structures luted with different cement types. Journal of dentistry. 2012 Feb 1;40:123-30.

24. Castillo-Oyagüe R, Lynch CD, Turrión AS, LópezLozano JF, Torres-Lagares D, Suárez-García MJ. Misfit and microleakage of implant-supported crown copings obtained by laser sintering and casting techniques, luted with glass-ionomer, resin cements and acrylic/urethanebased agents. Journal of dentistry. 2013 Jan 1;41:90-6.

25. Groten M,Axmann D, Pröbster L, Weber H. Determination of the minimum number of marginal gap measurements required for practical in vitro testing. The Journal of prosthetic dentistry. 2000 Jan 1;83:40-9.

26. Gonzalo E, Suárez MJ, Serrano B, Lozano JF. A comparison of the marginal vertical discrepancies of zirconium and metal ceramic posterior fixed dental prostheses before and after cementation. The Journal of prosthetic dentistry. 2009 Dec 1;102:378-84. 
27. Demir N, Ozturk AN, Malkoc MA. Evaluation of the marginal fit of full ceramic crowns by the microcomputed tomography (micro-CT) technique. European journal of dentistry. 2014 Oct;8:437.

28. Ural Ç, Burgaz Y, Saraç D. In vitro evaluation of marginal adaptation in five ceramic restoration fabricating techniques. Quintessence International. $2010 \mathrm{Jul} \mathrm{1;41.}$

29. Borges GA, Faria JS, Agarwal P, Spohr AM, CorrerSobrinho L, Miranzi BA. In vitro marginal fit of three all-ceramic crown systems before and after cementation. Operative dentistry. 2012 Oct;37:641-9.

30. Ortega R, Gonzalo E, Gomez-Polo M, Suárez MJ Marginal and Internal Discrepancies of Posterior ZirconiaBased Crowns Fabricated with Three Different CAD/CAM Systems Versus Metal-Ceramic. International Journal of Prosthodontics. 2015 Sep 1;28.

31. Nawafleh NA, Mack F, Evans J, Mackay J, Hatamleh MM. Accuracy and reliability of methods to measure marginal adaptation of crowns and FDPs: a literature review. Journal of Prosthodontics. 2013 Jul;22:419-28.

32. Gassino G, Monfrin SB, Scanu M, Spina G, Preti G Marginal adaptation of fixed prosthodontics: a new in vitro 360-degree external examination procedure. International Journal of Prosthodontics. 2004 Mar 1;17.

33. Zinelis S. Micro-CT evaluation of the marginal fit of different In-Ceram alumina copings. Department of Prosthodontics, School of Dentistry, National and Kapodistrian University. 2009.

34. Karlsson S. The fit of Procera titanium crowns: an in vitro and clinical study. Acta Odontologica Scandinavica. 1993 Jan 1;51:129-34.

35. Renne W, McGill ST, Forshee KV, DeFee MR, Mennito AS. Predicting marginal fit of CAD/CAM crowns based on the presence or absence of common preparation errors. The Journal of prosthetic dentistry. 2012 Nov 1;108:310-5.

36. Yeo IS, Yang JH, Lee JB. In vitro marginal fit of three all-ceramic crown systems. The Journal of prosthetic dentistry. 2003 Nov 1;90:459-64.

37. Mously HA, Finkelman M, Zandparsa R, Hirayama $\mathrm{H}$. Marginal and internal adaptation of ceramic crown restorations fabricated with $\mathrm{CAD} / \mathrm{CAM}$ technology and the heat-press technique. The Journal of prosthetic dentistry. 2014 Aug 1;112:249.

38. Neves FD, Prado CJ, Prudente MS, Carneiro TA, Zancopé K, Davi LR, Mendonça G, Cooper LF, Soares CJ. Micro- computed tomography evaluation of marginal fit of lithium disilicate crowns fabricated by using chairside CAD/CAM systems or the heat-pressing technique. The Journal of prosthetic dentistry. 2014 Nov 1;112:1134-40.

39. Anadioti E, Aquilino SA, Gratton DG, Holloway JA, Denry I, Thomas GW, Qian F. 3D and 2D marginal fit of pressed and CAD/CAM lithium disilicate crowns made from digital and conventional impressions. Journal of Prosthodontics. 2014 Dec;23:610-7.

40. Guess PC, Vagkopoulou T, Zhang Y, Wolkewitz M, Strub JR. Marginal and internal fit of heat pressed versus CAD/ CAM fabricated all-ceramic onlays after exposure to thermo-mechanical fatigue. Journal of dentistry. $2014 \mathrm{Feb}$ 1;42:199-209.

41. Ng J, Ruse D, Wyatt C. A comparison of the marginal fit of crowns fabricated with digital and conventional methods. The Journal of prosthetic dentistry. 2014 Sep 1; 112:555-60.

42. Lins L, Bemfica V, Queiroz C, Canabarro A. In vitro evaluation of the internal and marginal misfit of CAD/ CAM zirconia copings. The Journal of prosthetic dentistry. 2015 Mar 1;113:205-11.

43. Pradíes G, Zarauz C, Valverde A, Ferreiroa A, MartínezRus F. Clinical evaluation comparing the fit of all-ceramic crowns obtained from silicone and digital intraoral impressions based on wavefront sampling technology. Journal of dentistry. 2015 Feb 1;43:201-8.

44. Kokubo Y, Tsumita M, Kano T, Sakurai S, Fukushima S. Clinical marginal and internal gaps of zirconia all-ceramic crowns. Journal of Prosthodontic Research. 2011;55:40-3.

45. Yildiz C, Vanlioğlu BA, Evren B, Uludamar A, Özkan YK. Marginal-internal adaptation and fracture resistance of CAD/CAM crown restorations. Dental materials journal. 2013 Jan 31;32:42-7.

46. Anadioti E, Aquilino SA, Gratton DG, Holloway JA, Denry IL, Thomas GW, Qian F. Internal fit of pressed and computer-aided design/computer-aided manufacturing ceramic crowns made from digital and conventional impressions. The Journal of prosthetic dentistry. $2015 \mathrm{Apr}$ $1 ; 113: 304-9$

47. Sakrana AA. In vitro evaluation of the marginal and internal discrepancies of different esthetic restorations. Journal of Applied Oral Science. 2013 Dec;21:575-80.

48. Nakamura T, Dei N, Kojima T, Wakabayashi K. Marginal 
and internal fit of Cerec 3 CAD/CAM all-ceramic crowns. International Journal of Prosthodontics. 2003 May 1;16.

49. Nakamura T, Tanaka H, Kinuta S, Akao T, Okamoto K, Wakabayashi K, Yatani H. In vitro study on marginal and internal fit of CAD/CAM all-ceramic crowns. Dental materials journal. 2005;24:456-9.

50. Iwai T, Komine F, Kobayashi K, Saito A, Matsumura $\mathrm{H}$. Influence of convergence angle and cement space on adaptation of zirconium dioxide ceramic copings. Acta Odontologica Scandinavica. 2008 Jan 1;66:214-8.

51. Choi SH, Cheung HH. A multi-material virtual prototyping system. Computer-Aided Design. 2005 Jan 1;37:123-36.

52. Cvetkovic C. The development of a skeletal muscle bioactuator using 3-D stereolithography.

53. Naing MW, Chua CK, Leong KF, Wang Y. Fabrication of customised scaffolds using computer-aided design and rapid prototyping techniques. Rapid Prototyping Journal. 2005 Sep 1;11:249-59.

54. Stansbury JW, Idacavage MJ. 3D printing with polymers: Challenges among expanding options and opportunities. Dental Materials. 2016 Jan 1;32:54-64.

55. Pinto JM, Arrieta C, Andia ME, Uribe S, Ramos-Grez J, Vargas A, Irarrazaval P, Tejos C. Sensitivity analysis of geometric errors in additive manufacturing medical models. Medical engineering \& physics. 2015 Mar $1 ; 37: 328-34$.

56. Anusavice KJ, Shen C, Rawls R. Dental waxes, casting investments, and casting procedures. InPhillips' science of dental materials 2013. p.194-230. Saunders/Elsevier, St Louis.

57. Sorensen JA, Munksgaard EC. Interfacial gaps of resin cemented ceramic inlays. European journal of oral sciences. 1995 Apr;103:116-20.

58. Mou SH, Chai T, Wang JS, Shiau YY. Influence of different convergence angles and tooth preparation heights on the internal adaptation of Cerec crowns. The Journal of prosthetic dentistry. 2002 Mar 1;87:248-55.

59. Fathi HM, Al-Masoody AH, El-Ghezawi N, Johnson A. The Accuracy of Fit of Crowns Made From Wax Patterns Produced Conventionally (Hand Formed) and Via CAD/ CAM Technology. The European journal of prosthodontics and restorative dentistry. 2016 Mar;24:10-7.

60. Shamseddine L, Mortada R, Rifai K, Chidiac JJ. Fit of pressed crowns fabricated from two CAD-CAM wax pattern process plans: A comparative in vitro study. The Journal of prosthetic dentistry. $2017 \mathrm{Jul}$ 1;118:49-54.

61. Ender A, Attin T, Mehl A. In vivo precision of conventional and digital methods of obtaining complete-arch dental impressions. The Journal of prosthetic dentistry. 2016 Mar 1;115:313-20.

62. Kirsch C, Ender A, Attin T, Mehl A. Trueness of four different milling procedures used in dental CAD/CAM systems. Clinical oral investigations. 2017 Mar 1;21:551-8.

63. Vandenbroucke B, Kruth JP. Selective laser melting of biocompatible metals for rapid manufacturing of medical parts. Rapid Prototyping Journal. 2007 Aug 7;13:196-203. 